\title{
TRADUÇÃo
}

\section{TRABALHO GLOBAL: \\ UM NÃO TÃO GRAN FINALE \\ E TALVEZ UM NOVO COMEÇO}

\subsection{2/mvt.v8i14.15031 \\ Marcel Van der Liden'}

Movimentos tradicionais de trabalhadores se encontram em dificuldades em quase toda a parte. ${ }^{2}$ Eles foram severamente fragilizados pelas transformaçóes políticas e econômicas dos últimos quarenta anos. Seu núcleo é composto por três formas de organizaçôes de movimento social: cooperativas, sindicatos e partidos de trabalhadores. Todos esses três tipos organizacionais estáo em declínio, embora esse seja um desenvolvimento desigual com vastas diferenças entre países e regióes. Estamos atravessando um período transicional no qual antigas estruturas organizativas não parecem mais funcionar bem, enquanto novas estruturas ainda estão em suas etapas iniciais.

\section{COOPERATIVAS DE CONSUMO}

Desde os anos 1940 e 1950, as cooperativas de consumo, como todos os empreendimentos sob o capitalismo, foram crescentemente forçadas a concentrar capital, em decorrência da melhoria das instalaçóes de transporte e de novas formas de varejo. Essa tendência se manifestou parcialmente no declínio do número de cooperativas e no crescimento da base de associados de cada unidade cooperativista (PESTOFF, 1991, p. 234; GURNEY, 1996 p. 242). Frequentemente, a média de idade dos membros aumentou, uma vez que membros mais velhos continuaram fiéis às suas cooperativas, enquanto membros mais novos não foram incorporados. Em geral, cooperativas de consumo foram condenadas por dificuldades que decorreram de seu papel pioneiro. Estabelecidas em uma era na qual pequenos comerciantes controlavam o varejo, elas estavam inicialmente em vantagem. Suas extensas operaçóes eram mais economicamente racionais e produziam ganhos de escala. Em resposta, comerciantes se uniram e criaram redes varejistas, centrais de compras, lojas de autoatendimento, supermercados, shopping centers e coisas do tipo. Esses novos tipos de negócios utilizavam nomes de marcas, sistemas cumulativos de resgate de crédito, preços baixos e anúncios atraentes. Como resultado, a vantagem competitiva das cooperativas de consumo se deteriorou rapidamente. A base excedente (o excedente dividido pelas vendas) diminuiu, o que foi acompanhado pelos dividendos distribuídos aos membros e pelas oportunidades de inovação e investimento. Muitas cooperativas

\footnotetext{
$1 \quad$ Universidade de Amsterdam, Holanda. E-mail: mvl@iisg.nl

2 Este artigo é parcialmente baseado em uma nota de pesquisa escrita para o International Panel on Social Progress (www. ipsp.org). Beneficiei-me de sugestóes feitas por Naila Kabeer, Ronaldo Munck e Peter Wagner. Alguns parágrafos foram reaproveitados de Van der Linden (2010, 2015).
} 
de consumo enfrentaram dificuldades financeiras e se depararam com um sério dilema em seus esforços para evitar a falência. Suas escolhas limitadas incluíam a fusão com negócios capitalistas convencionais, tornar-se uma companhia de sociedade limitada ou tomar emprestado de bancos quantias consideráveis. Em cada caso, elas deixavam de ser cooperativas autônomas. Outra abordagem envolvia combater a competição crescente por meio da modernização e expansão operacional, aumentando a assim a distância social entre associados e administradores, bem como reduzindo ainda mais o envolvimento dos associados, minando a natureza cooperativista da organização.

\section{SINDICATOS}

Sindicatos de massa independentes se originaram no século XIX e existem hoje em grande parte do mundo - ainda que também existam importantes regióes em que eles possuem quase nenhuma influência. $\mathrm{O}$ exemplo mais marcante de uma economia capitalista de rápido crescimento sem sindicatos independentes é a República Popular da China (RPC). Ela abriga a maior organizaçáo de trabalhadores do mundo, a Federaçáo Nacional dos Sindicatos da China (FNSCh), que possui mais de 280 milhões de membros. No entanto, não se trata de um sindicato independente, mas de uma correia de transmissão do Partido Comunista Chinês. A maioria dos numerosos conflitos trabalhistas na República Popular não ocorre com o apoio da FNSCh (BAI, 2012). Em países com organizaçóes independentes de trabalhadores, a densidade sindical (a porcentagem da força de trabalho total associada aos sindicatos) tem em geral diminuído. A Tabela 1 apresenta as tendências em um conjunto de países com mais de 50 milhóes de habitantes em 2010, para o período entre 1960 e 2013.

Tabela 1 - Densidade sindical em países selecionados, 1960 - 2013

\begin{tabular}{|c|c|c|c|c|c|c|c|}
\hline País & 1960 & 1970 & 1980 & 1990 & 2000 & 2010 & 2013 \\
\hline Brasil & n.d. & n.d & $20.8(196)$ & 26.7 & 28.3 & 26.5 & 16.6 \\
\hline RP China & n.d. & n.d. & $(58.6)$ & $(76.6)$ & $(62.3)(1997)$ & (34.7) & $(42.6)$ \\
\hline Franca & 19.6 & 217 & 18.3 & 10.0 & 8.0 & 79 & 77 \\
\hline Alemanha & $34.7^{*}$ & $32.0^{\star}$ & $34.9^{\star}$ & 31.2 & 24.6 & 18.6 & $17.7+$ \\
\hline India & n.d. & n.d. & n.d. & n.d. & $13.8(2004)$ & $10.2(2009)$ & $9.8(2012)$ \\
\hline Itália & 24.7 & 37.0 & 49.6 & 38.8 & 34.8 & 36.0 & $36.9^{t}$ \\
\hline Japăo & 32.9 & 35.1 & 31.1 & 25.4 & 21.5 & 18.4 & 17.8 \\
\hline Malásia & n.d. & n.d. & n.d. & 16.5 & 107 & 91 & 9.4 \\
\hline Mexico & & & & & $15.6^{t}$ & $14.4^{t}$ & $13.6^{t}$ \\
\hline Filipinas & n.d. & n.d. & 27.0 & 29.7 & 27.1 & 8.7 & 8.5 \\
\hline Federação & & 100.0 (1968) & $100.0(1979)$ & 72.0 & 55.6 (1999) & 30.7 & 27.8 \\
\hline Russa & & & & & & & \\
\hline Africa do Sul & n.d. & n.d. & n.d. & n.d. & $39.1^{\dagger}$ & $29.7^{t}$ & n.d. \\
\hline Coréia do Sul & n.d. & n.d. & n.d. & n.d. & $11.4^{t}$ & $9.7^{t}$ & n.d. \\
\hline Turquia & 10.8 & 25.9 & 42.1 & 24.0 & 12.4 & 7.0 & 6.5 \\
\hline Reino Unido & 40.4 & 44.8 & 51.7 & 39.7 & 30.1 & 27.1 & $25.4^{t}$ \\
\hline $\begin{array}{l}\text { Estados } \\
\text { Unidos }\end{array}$ & n.d. & $23.5 \#$ & 19.5 \# & $15.5 \#$ & $\begin{array}{c}12.9^{\dagger} \\
12.8 \#\end{array}$ & $11.4^{t}$ & $10.8^{t}$ \\
\hline
\end{tabular}

* Alemanha = Alemanha Ocidental para 1960 a 1990. ${ }^{\dagger}$ Números da OCDE (stats.oecd.org). ${ }^{\dagger}$ ILOSTAT (www.ilo.org/ilostat). \# Jelle Visser, (2006: 38-49). Países incluídos foram aqueles que tinham uma população maior do que 50 milhões em 2010 . 0 s seguintes países não foram incluídos devido à falta de dados: Argentina, Bangladesh, Colômbia, República Democrática do Congo, Egito, Etiópia, Indonésia, Irã, Myanmar, Nigéria, Paquistão, Tanzânia e Vietnã. Todas as porcentagens indicam o total de membros de sindicatos em relação aos assalariados empregados, a não ser que esses números não estejam disponíveis. Fonte adicional: ICTWSS Database, Amsterdams Instituut voor Arbeidsstudies (www.uva-aias.net/207), versão 4, abril de 2013.

Em escala global, a densidade sindical é praticamente insignificante. Os sindicatos independentes organizam apenas uma pequena porcentagem de sua base potencial em todo o mundo, e a maioria deles se encontra na região relativamente rica do Atlântico Norte. De longe, a organização guarda-chuva global mais importante é a Confederaçáo Sindical Internacional (CSI), fundada em 2006 como uma fusão de duas organizaçôes mais antigas, a secular e reformista Confederação Internacional de Organizaçôes Sindicais Livres (CIOSL) e a cristã Confederação Mundial do 
Trabalho (CMT). Em 2014, a CSI estimou que cerca de 200 milhóes de trabalhadores pertenciam a sindicatos (excluindo os da China) e que 176 milhóes deles estavam organizados na CSI ${ }^{3}$. A CSI também estima que o número total de trabalhadores é aproximadamente 2,9 bilhóes (dos quais 1,2 bilhão estão na economia informal). Portanto, a densidade sindical global hoje não passa de 7 por cento! (ITUC, 2014, p. 8)

Um conjunto de fatores contribuiu para a fragilidade dos sindicatos. Em primeiro lugar, a composição da classe trabalhadora está mudando. Os sindicatos encontram dificuldades para organizar os empregados no setor financeiro ou de serviços. O rápido crescimento da economia informal é um fator adicional de complicação, uma vez que os trabalhadores são submetidos a contratos de curta duração, tendem a trocar de emprego com frequência e trabalham sob condiçóes muitas vezes precárias. Outro fator importante é o que o economista do trabalho Richard Freeman (2010) chamou de "choque da oferta de trabalho", que se manifestou desde o início dos anos 1990. Com a entrada de trabalhadores chineses, indianos russos e outros na economia global, efetivamente houve uma duplicação do número de trabalhadores que produzem para os mercados internacionais nas últimas duas décadas.

Um declínio na proporção global entre o capital e o trabalho desloca o equilíbrio de poder nos mercados na direçấo do capital, em detrimento dos salários pagos aos trabalhadores, à medida que mais trabalhadores competem para trabalhar com aquele capital. [...] Mesmo que se considere a alta taxa de poupança entre os ingressantes - o Banco Mundial estima que a China tem uma taxa de poupança de $40 \%$ do PIB -, levará cerca de 30 anos para que o mundo volte a atingir a proporção capital / trabalho existente entre os países que anteriormente constituíam a economia global. A existência do dobro de trabalhadores e aproximadamente a mesma quantidade de capital exerce grande pressão sobre os mercados de trabalho ao redor do mundo. Essa pressão afetará os trabalhadores dos países em desenvolvimento que tradicionalmente participaram da economia global, assim como os trabalhadores dos países avançados (FREEMAN, 2010, s.p.).

Em segundo lugar, ocorreram transformaçôes econômicas significativas. O crescimento do investimento estrangeiro direto nos países centrais e na semiperiferia da economia mundial tem sido impressionante, e as corporaçóes transnacionais e blocos comerciais multiestatais - a exemplo da União Europeia, o Tratado Norte-Americano de Livre Comércio e o Mercosul - se multiplicaram, aumentando a terceirizaçáo e a realocação da produçáo. O Brasil, a Índia e principalmente a China são novos jogadores importantes que mudam as regras do jogo. Isso é acompanhado por novas instituiçóes supranacionais, como a Organização Mundial do Comércio, estabelecida em 1995.

Em terceiro lugar, em muitos países tem ocorrido uma forte ofensiva neoliberal contra os sindicatos de estilo antigo e seu modus operandi: a prática dominante de negociação coletiva tem se tornado crescentemente descentralizada e os contratos individuais de trabalho se tonaram muito

3 Esse cálculo é provavelmente enganoso. Uma parte significativa, mas desconhecida, dos membros dos sindicatos é formada por aposentados. É provável, portanto, que o número de trabalhadores empregados ou empregáveis seja menor. 
mais disseminados do que antes. Também houve ataques muito diretos aos sindicatos, notavelmente nos países que passaram por mudanças neoliberais de regime como os Estados Unidos e o Reino Unido. Sindicatos enfraquecidos se deparam com cada vez mais competição de estruturas alternativas que estão mais bem adaptadas ao novo estilo de relações de trabalho. No Brasil, na África do Sul, nas Filipinas e na Coréia do Sul, movimentos militantes de trabalhadores (sindicatos de movimento social) emergiram (SCIPES, 2014). Novas formas de sindicalismo de base por fora dos canais estabelecidos têm aparecido desde os anos 1970, com conexóes internacionais ao nível do chão-de-fábrica "passando completamente ao largo dos secretariados, que são vistos como excessivamente submissos às burocracias de seus vários afiliados nacionais" (HEROD, 1997, p. 184). Um exemplo bem conhecido é a Transnationals Information Exchange (TIE), um centro no qual um número considerável de grupos de pesquisa e de ativistas trocam informaçôes sobre corporaçôes transnacionais. A ineficácia dos sindicatos de estilo antigo é sublinhada pela tendência crescente entre os secretariados sindicais internacionais (agora chamados de sindicatos globais) de recrutar membros diretamente na periferia. Podemos pensar, por exemplo, nas atividades da Union Network International (o sindicato global do setor de serviços), que passou a recrutar especialistas de Tecnologia da Informação na Índia diretamente, por fora dos sindicatos locais.

\section{PARTIDOS DE TRABALHADORES}

Partidos trabalhistas, social-democratas e comunistas são geralmente considerados representantes políticos da classe trabalhadora. Os partidos mais antigos, os partidos social-democratas e trabalhistas, não têm obtido bons resultados eleitorais. A tabela 2 indica que dos 15 partidos listados, 12 atingiram seu ápice entre 1940 e 1989; na Suíça isso aconteceu antes (anos 1930), enquanto em Portugal e no Brasil aconteceu depois (início do século XXI). Mais importante, porém, é que essa família de partidos enfrenta um problema fundamental de identidade. As políticas social-democratas e trabalhistas, desde os anos 1930 e 1940, têm se baseado em dois pilares: o social-keynesianismo e uma subcultura partidária "vermelha” específica com suas próprias associações esportivas, clubes de mulheres, organizaçóes para amantes da natureza, cooperativas de consumo, jornais, grupos de teatro e assim por diante.

A reversão sociocultural e econômica derrubou os dois "pilares" do palco social-keynesiano, desde os anos 1960 e 1970, à medida que as redes partidárias subculturais - organizaçóes de juventude, de mulheres, esportivas etc. - se desintegraram e que o social-keynesianismo se tornou menos viável devido a crises econômicas e à globalização. Muitos desafios tiveram de ser enfrentados mais ou menos simultaneamente. $\mathrm{O}$ centralismo tradicional teve que se ver com movimentos de base e o feminismo com a cultura androcêntrica convencional. Além disso, o movimento ambientalista teve que ser levado a sério sem que se abandonasse a busca pelo crescimento econômico (a condição para a redistribuição social em um contexto capitalista). A confusão generalizada resultou em um aumento enorme de eleitores vacilantes, envelhecimento e diminuição do número de membros, e o virtual desaparecimento de membros proletários ativos, enfraquecendo assim os laços sociais com os sindicatos.

Partidos comunistas são a segunda grande forma política. A maior parte deles surgiu ou cresceu significativamente em três ondas: de meados de 1918 a 1923, após a Revolução de Outubro; nos 
anos 1930 como uma resposta à depressão econômica; e durante e imediatamente depois da Segunda Guerra Mundial. Alguns desses partidos ainda têm uma base bastante sólida, embora usualmente pequena, como os de Portugal, Espanha e Grécia. Todos esses partidos se desenvolveram sob ditaduras de direita e são caracterizados por sua intransigência. Similarmente, o influente Partido Comunista Sul-Africano (SACP) parece ainda exercer influência significativa sobre a política do Congresso Nacional Africano (ANC).

TABELA 2 - RESULTADO PARLAMENTAR MÉDIO DE PARTIDOS SOCIAL-DEMOCRATAS E TRABALHISTAS SELECIONADOS, 1920-2015

\begin{tabular}{|c|c|c|c|c|c|c|c|c|c|c|}
\hline & $\begin{array}{c}1920- \\
1929\end{array}$ & $\begin{array}{c}1930- \\
1939\end{array}$ & $\begin{array}{c}1940- \\
1949\end{array}$ & $\begin{array}{c}1950- \\
1959\end{array}$ & $\begin{array}{c}1960- \\
1969\end{array}$ & $\begin{array}{c}1970- \\
1979\end{array}$ & $\begin{array}{c}1980- \\
1989\end{array}$ & $\begin{array}{c}1990- \\
1999\end{array}$ & $\begin{array}{c}2000- \\
2009\end{array}$ & $\begin{array}{c}2010- \\
2015\end{array}$ \\
\hline Austrália & 45.2 & 32.4 & 46.5 & 46.3 & 45.1 & 45.4 & 47.0 & 40.8 & 39.2 & 35.7 \\
\hline Áustria & 39.3 & 41.1 & 41.7 & 43.3 & 50.0 & 45.4 & $47.6^{*}$ & 37.3 & 33.7 & $26.8^{*}$ \\
\hline Bélgica & 36.7 & 33.1 & 30.7 & 35.9 & 31.0 & 26.6 & 28.0 & 23.2 & 24.0 & 21.7 \\
\hline Brasil & - & - & - & - & - & - & - & 12.1 & 16.8 & 15.4 \\
\hline Dinamarca & 34.5 & 43.9 & 39.1 & 40.2 & 39.1 & 33.6 & 30.9 & 36.0 & 26.8 & 25.6 \\
\hline França & 19.1 & 20.2 & 20.9 & 15.1 & 15.9 & 21.0 & 35.3 & 34.6 & 38.8 & $29.4^{\star}$ \\
\hline Alemanha & 29.3 & 21.2 & 29.2 & $30.3 \#$ & $39.4 \#$ & $44.2 \#$ & $39.4 \#$ & 36.9 & 31.9 & $25.7^{\star}$ \\
\hline Itália & $24.7^{\star}$ & - & {$[20.7]$} & 13.5 & 13.8 & 9.7 & 12.9 & $7.9^{\star *}$ & - & - \\
\hline Holanda & 22.0 & 21.7 & 27.0 & 30.7 & 25.8 & 28.6 & 31.0 & 26.5 & 21.2 & 24.8 \\
\hline Noruega & 25.5 & 38.0 & 43.4 & 47.5 & 45.5 & 38.8 & 27.4 & 36.0 & 30.8 & $30.8^{*}$ \\
\hline Portugal & - & - & - & - & - & 35.2 & 27.6 & 39.0 & 39.8 & 30.2 \\
\hline Espanha & - & 23.1 & - & - & - & 30.4 & 44.1 & 38.2 & 40.2 & 25.4 \\
\hline Suécia & 36.0 & 43.8 & 48.8 & 45.6 & 48.4 & 43.7 & 44.5 & 39.8 & 37.5 & 30.9 \\
\hline Suíça & 25.5 & 27.5 & 27.4 & 26.5 & 25.1 & 24.1 & 20.7 & 20.9 & 21.4 & $18.7^{\star}$ \\
\hline Reino Unido & 37.7 & 34.4 & $49.7^{\star}$ & 46.3 & 46.1 & 39.1 & 29.2 & 38.7 & 38.0 & 29.7 \\
\hline Apens uma & & & & & & & & & & \\
\hline
\end{tabular}

*Apenas uma eleição ** Partido dissolvido em novembro de 1994 \# Números entre 1950 e 1990 se referem à Alemanha Ocidental.

No entanto, para a maior parte dos partidos comunistas, o ponto alto ocorreu na década de 1940; agora, muitos deles enfrentam tempos difíceis. Em um número significativo de países, esses partidos se dissolveram após declínio eleitoral, divisōes ou falência financeira. Esse foi o caso na Grã-Bretanha (dissolvido em 1991), Itália (desmobilizado em 1991), Finlândia (falência em 1991) e Brasil (golpe interno e cisão em 1992). Outros partidos passaram por fusões, por exemplo no México (fundação do Partido Socialista Unificado em 1981), Dinamarca (formação da Aliança Vermelha e Verde em 1989) e Holanda (fundação do partido Esquerda Verde em 1989). Até mesmo o Partido Comunista da Índia-Marxista (CPI-M) em Bengala Ocidental, que recebeu a maioria dos votos em toda uma série de eleiçóes dos anos 1970 até 2011, foi recentemente reduzido a um ator de menor importância (conquistando apenas dois de 42 assentos), em decorrência de suas violentas políticas neoliberais. 


\section{SINAIS DE RENOVAÇÃO}

Em linhas gerais, o que foi apresentado anteriormente parece sugerir três coisas. Em escala global, as cooperativas de consumo ou não estão indo bem, ou se transformaram em empresas varejistas nas quais os membros não controlam democraticamente os negócios. Os sindicatos não são apenas uma força fraca, mas seu poder também está em declínio; em muitos países, os sindicatos perderam seus aliados naturais, os partidos de trabalhadores, seja porque esses partidos desapareceram, seja porque eles adotaram uma variedade do neoliberalismo. Como consequência, Organizaçóes Não-Governamentais (ONGs) locais e internacionais tomaram parcialmente para si atividades que anteriormente eram responsabilidade do movimento sindical internacional, como a luta pela regulação e abolição do trabalho infantil. O declínio dos movimentos operários parece ser quase que completamente abrangente.

Nessas circunstâncias, quais são as perspectivas para os movimentos dos trabalhadores? No longo prazo, as coisas podem não ser tão desanimadoras quanto parecem hoje. Diversos fatores podem se transformar, o que possibilitaria um futuro mais otimista.

Em primeiro lugar, os conflitos de classe não diminuirão e trabalhadores por todo o mundo continuarão a sentir a sempre presente necessidade por organizaçóes e formas de luta eficazes. Uma confirmação indireta dessa afirmação vem dos movimentos religiosos e nacionalistas que parcialmente ocupam o vazio social atualmente existente por meio do redirecionamento dos conflitos de classe. Eles oferecem a seus apoiadores formas elementares de seguridade social e redes de confiança, assim como autoestima e objetivos de vida claros. Muitas pessoas pobres são atraídas por esses movimentos, em todas as suas variedades - dos movimentos pentecostais da América Latina e da África Subsaariana ao salafismo no Norte da África, Oriente Médio e Ásia Central. A juventude precarizada nas cidades capitalistas industriais também parece às vezes ser atraída por grupos que oferecem uma nova certeza religiosa. O historiador Sabyasachi Bhattacharya (2016, p. 2) chama essa tendência de "vernacularização da política operária"; ela cria "solidariedade de pessoas com uma causa comum que pode ser social ou cultural, ou às vezes regressivamente religiosa; a solidariedade assim obtida pode ser e é utilizada para afirmar uma agenda que é paralela à agenda sindical ou a substitui". Um exemplo de direita claro é o movimento hindu-fascista Shiv Sena, que ganhou influência após a derrota da grande greve dos trabalhadores têxteis em Mumbai em 1980-1981. As mazelas sociais da casualização do trabalho, empobrecimento, aumento da criminalidade cotidiana e tráfico de pessoas tornaram os Shiv Sainiks populares rapidamente. Eles ofereceram aos pobres não apenas honra, status e autorrespeito, mas também cooperaram com "sindicatos" amarelos, que ofereciam alguma proteção (HEUZÉ-BRIGUANT, 1999).

Em segundo lugar, a força de trabalho global é maior do que nunca. Um estudo recente da Organização Internacional do Trabalho (OIT) revelou que no período 1980-2005 a força de trabalho no Oriente Médio e Norte da África havia crescido 149\%. Na África Subsaariana, América Latina e Caribe, ela havia aproximadamente dobrado, no Leste e Sul da Ásia havia aumentado 73\%, e no Sudeste Asiático 60\% (KAPSOS, 2007). Ao mesmo tempo, enormes transformaçóes estão ocorrendo dentro de diferentes regióes. Uma história de migração do campo para megacidades em expansão está em andamento. No ano 2000, o Escritório Nacional de Estatísticas da República Popular da China estimou que havia 113 milhóes de trabalhadores migrantes rurais no país. Dez anos mais tarde, esse número havia mais do que dobrado, chegando a 240 milhóes, incluindo 150 milhôes trabalhando fora de suas áreas de origem. Desses 150 milhôes, cerca de $72 \%$ estavam empregados nas indústrias manufatureira, de construção, alimentícia, do comércio varejista e atacadista, e da hospitalidade (CLB, 2012, p. 4). Na índia, a migração interna de trabalhadores explodiu 
desde os anos 1990, e a taxa de migração temporária e sazonal foi mais alta em regióes pobres como Nagaland e Madya Pradesh (BHAGAT; MOHANTY, 2009).

Em terceiro lugar, essas transformaçôes são frequentemente acompanhadas por uma intensificação nas lutas sociais. Na Indonésia, a Konfederasi Serikat Pekerja Indonesia (Confederação Sindical Indonésia) organizou uma greve nacional em 3 de outubro de 2012 e uma segunda demandando $50 \%$ de aumento do salário-mínimo - em 31 de outubro e $1^{\circ}$ de novembro de 2013. Essas não foram greves realmente gerais, mas ainda assim participaram centenas de milhares de trabalhadores, em particular na região de Jacarta. Na Índia, em 20 e 21 de fevereiro de 2013, mais de cem milhóes de trabalhadores pelo país fizeram greve por uma lista de demandas que incluía um salário-mínimo indexado pela inflação, segurança alimentar universal e pagamento igual para trabalhos iguais. Na China, a escassez de mão-de-obra que começou a aparecer a partir de 2004 levou a um rápido crescimento dos protestos de trabalhadores, que "não apenas aumentaram em número, mas mudaram o foco de uma resposta reativa a violaçôes de direitos trabalhistas na direção de demandas mais proativas por salários maiores e melhores condiçôes de trabalho" (CLB, 2012, p. 5). A Academia Chinesa de Ciências Sociais relatou que houve mais de 60.000 dos chamados "incidentes de massa" (protestos populares feitos por trabalhadores assalariados e outros, como camponeses e o grupo quase religioso Falun Gong) em 2006, e mais de 80.000 em 2007. Desde então, estatísticas oficiais sobre "incidentes de massa" não foram mais publicadas, mas especialistas acreditam que nos últimos anos o número cresceu ainda mais (CLB, 2012, p. 9). Desde o início da crise econômica, mais de 30 greves nacionais ocorreram na Grécia, enquanto Espanha e Portugal testemunharam várias greves gerais. A dramática derrubada da ditadura de Mubarak no Egito em 2011 não poderia ter acontecido sem o forte apoio do movimento operário. $\mathrm{Na}$ África do Sul, greves massivas e frequentemente violentas se sucedem umas às outras com rapidez. Há, portanto, muita militância, mas isso não é acompanhado pela força das organizaçóes operárias.

Em quarto lugar, durante a última década protestos sociais cresceram em todas as regióes do mundo:

Apesar da falta de exatidão na medição, dados das últimas décadas apontam para um padrão relativamente claro de frequência crescente. Os grandes protestos se multiplicaram na segunda metade dos anos 1980 e no início dos 1990, coincidindo com o que é comumente chamado de terceira onda de democracia, mas entâo diminuíram significativamente ao longo dos 1990 e da primeira metade dos anos 2000. Os protestos começaram a acelerar novamente na segunda metade dos 2000 e chegaram a um ápice nos últimos cinco anos (i.e., 2011-2016) (CARROTHERS; YOUNGS, 2015, p. 5; ORTIZ et al., 2013; ECONOMIST INTELLIGENCE UNIT, 2013).

Em sua grande maioria, os eventos de protesto direcionam reclamaçóes a seus próprios governos nacionais e demandam que esses governos desenvolvam políticas econômicas, sociais e ambientais que sirvam aos interesses da população e não apenas dos ricos e poderosos. As demandas apresentadas por aqueles que protestam são em geral variadas e as formas assumidas pelos protestos são heterogêneas. Os protestos se opóem a muitas coisas: a eliminação de subsídios para comidas e combustíveis; cortes de salários; aumentos de impostos sobre bens e serviços básicos; a degradação da seguridade social; a reforma dos sistemas de previdência e saúde; a flexibilização do trabalho; mas também poluição, guerra, estupros e influência corporativa. A falta de "democracia real" é uma questão recorrente. Protestos são mais frequentes em países de alta-renda, e se tornam violentos com 
mais frequência em países de baixa-renda. A maior parte dos protestos náo conquista um alívio em relação às queixas apresentadas, pelo menos no curto prazo (ORTIZ et al., 2013, p. 34).

Em quinto lugar, há também sinais explícitos de uma renovação. Campanhas de organização de trabalhadores até então desorganizados em hospitais e no setor do cuidado em geral têm crescido nos últimos anos. O surgimento da Rede Internacional de Trabalhadoras Domésticas, desde 2009, e sua campanha que resultou na Convenção 189 da OIT sobre Trabalho Decente para Trabalhadores Domésticos (OIT, 2011) foi uma inspiração para muitos. A onda de greves de trabalhadores encarcerados nos Estados Unidos atual revela que novos segmentos da classe trabalhadora estão começando a se mobilizar. Em muitos países, os sindicatos estão tentando se abrir a trabalhadores "informais" e “ilegais". Bastante espetacular é a Nova Iniciativa Sindical da Índia (NTUI), fundada em 2006, que reconhece a importância tanto do trabalho remunerado quanto do trabalho não-remunerado das mulheres; ela tenta organizar não apenas o setor "formal”, mas também trabalhadores temporários, casuais, domésticos, os autônomos e os pobres urbanos e rurais; tenta, ainda, reestruturar os quadros de negociação coletiva de acordo com essa atuação.

\section{PERSPECTIVAS}

Há um importante obstáculo à renovação dos movimentos operários, o que faz com que sucessos sejam difíceis de alcançar: durante as últimas quatro ou cinco décadas, os Estados nacionais perderam muito de sua soberania, mas essa perda de poder não foi compensada por autoridades supranacionais (ou mundiais). Vivemos em um período transicional em que muitos desafios não podem ser resolvidos por autoridades nacionais, mas também por autoridades supranacionais (se é que algum dia o serão).

No mundo global contemporâneo, não há um equivalente ao Estado-nação ao nível mundial que possa implementar políticas fiscais e de bem-estar, controles antitruste, leis trabalhistas e ambientais orientadas pela regulação dos mercados e pela correção de falhas de mercado. Não há um judiciário mundial independente que possa controlar e sancionar comportamentos ilegais. Não há uma polity democrática ao nível mundial (MARTINELLI, 2005, p. 247).

Isso ajuda a explicar a atitude "negativa" de muitos movimentos sociais que dizem "náo" a certos desenvolvimentos sem apresentar uma alternativa positiva, porque isso requereria uma autoridade mundial. Não obstante, a ação transacional focada em Estados é possível, mesmo sob condiçóes essas condiçôes adversas - seja por meio da pressão sobre governos nacionais para que coordenem políticas através de fronteiras, seja pelo exemplo de atividades locais que podem inspirar movimentos em outras partes do mundo.

Um novo movimento operário terá que encontrar uma abordagem internacionalista baseada na solidariedade transfronteiras, mesmo sob essas condiçóes adversas. Parcialmente, ele pode encontrar suas fundaçóes nos antigos movimentos operários, mas estes terão que se transformar consideravelmente. Os contornos do novo sindicalismo internacional continuam a ser vagos, mas diversas condiçôes mínimas já estão aparentes de forma clara. Elas incluem o seguinte:

O grupo-alvo deve ser demarcado novamente. A primeira fase da demarcação das classes trabalhadoras no século XIX foi extremamente estreita e eurocêntrica, e precisa ser revista e expandida. Um número considerável de sindicatos na periferia 
e na semiperiferia abandonaram a antiga demarcaçáo, recrutando todos os tipos de trabalhadores subalternos.

Não deve haver dúvida de que o grupo-alvo redefinido não será mais dominado por homens brancos da regiáo do Norte Atlântico, mas por mulheres e pessoas de cor, muitas em formas de emprego autônomo, empregos precários e servidão por dívida.

A estrutura dual do movimento sindical internacional - cooperação das confederaçôes nacionais na CSI em conjunto com as Federaçóes Sindicais Globais - é uma problemática relíquia do passado e provavelmente será descartada. Provavelmente, a melhor opçáo seria uma nova estrutura unitária que facilite a inclusão de "novos" grupos-alvo nos sindicatos globais. Os sindicatos precisarão transformar drasticamente seus sistemas operacionais para ajudar esses "novos" trabalhadores a defender seus interesses de forma eficaz. Isso também implica o fim da centralidade das estratégias de negociação coletiva.

A abordagem de certa forma autocrática que prevalece hoje no movimento sindical internacional deve ser substituída por uma abordagem democrática, e pela maior participação de trabalhadores da base. As possibilidades oferecidas pela internet podem ser uma contribuição positiva para uma estrutura renovada como essa.

Muito embora o lobbying em relação a governos e organizaçóes transnacionais tenha sido até hoje a atividade principal do movimento sindical internacional (com a exceção notável da campanha anti-apartheid dos anos 1980), e ainda que esforços sejam feitos para cultivar a boa-vontade dos Estados, uma ação efetiva exige muito mais esforço em medidas ativas, como boicotes, greves e coisas desse tipo, o que, por sua vez, demanda um fortalecimento substantivo das estruturas internas.

A questão é se o movimento sindical internacional existente está à altura desses desafios. É provável que a formaçáo de novos movimentos seja um processo difícil, atravessado por experiências de fracasso e momentos de crise aguda. Estruturas organizacionais e padróes de comportamento que existem há mais de um século não são facilmente transformados. Além disso, é altamente improvável que novas estruturas e padróes sejam conformados por reformas a partir de cima, por meio de lideranças centralizadas. Se há algo que a história nos ensinou, é que as estruturas sindicais quase nunca se desenvolvem suavemente com base em uma engenharia passo a passo. Elas são geralmente o resultado de conflitos e experimentos arriscados. A pressáo a partir de baixo (por meio de redes competitivas e modelos alternativos de ação) será um fator muito importante para determinar esse resultado.

\section{REFERÊNCIAS}

BAI, Ruixue. The Role of the All China Federation of Trade Unions: Implications for Workers Today. In: BAI, Ruixue; JETIN, Bruno; ROUSSET, Pierre (org.) China's Rise: Strength and Fragility. London: Merlin, 2012. 
BHAGHAT, R.B.; MOHANTY, S. Emerging Pattern of Urbanization and the Contribution of Migration in Urban Growth in India. Asian Population Studies, [s.l.], vol. 5 n. 1, p. 5-20, 2009.

CAROTHERS, Thomas; YOUNGS, Richard. The Complexities of Global Protests. Washington, DC: Carnegie Endowment for International Peace, 2015.

CHINA LABOUR BULLETIN (CLB). A Decade of Change: The Workers' Movement in China 20002010. CLB Research Report, March. Hong Kong: CLB, 2012.

CHINA LABOUR BULLETIN (CLB). Searching for the Union. The Workers' Movement in China 2011-13. CLB Research Report, February. Hong Kong: CLB, 2014.

ECONOMIST INTELLIGENCE UNIT. Rebels without a Cause: What the Upsurge in Protest Movements Means for Global Politics, 2013. Disponível em: http://www.eiu.com/ProtestUpsurge. Acesso em: 29 jun. 2021.

FREEMAN, Richard. What Really Ails Europe (and America): The Doubling of the Global Labor Force. The Globalist, 5 March, 2010.

GURNEY, Peter. Co-operative Culture and the Politics of Consumption in England, 1870-1930. Manchester and New York: Manchester University Press, 1996.

HEUZÉ-BRIGUANT, Gérard. Populism and the Workers Movement: Shiv Sena and Labour in Mumbai. Journal of South Asian Studies, [s.l.], vol. 22 n. 2, p. 119-148, 1999.

HEROD, Andrew. Labor as an Agent of Globalization and as a Global Agent. In: COX, Kevin R. (Org.) Spaces of Globalization: Reasserting the Power of the Local. New York: The Guilford Press, 1997.

OIT - INTERNATIONAL LABOUR ORGANIZATION (ILO). Convention 189 on Decent Work for Domestic Workers. Geneva: ILO, 2011.

INTERNATIONAL TRADE UNION CONFEDERATION (ITUC). Building Workers' Power: Congress Statement. Berlin: ITUC, 2014.

KAPSOS, Steven. World and Regional Trends in Labour Force Participation: Methodologies and Key Results. Geneva: ILO, 2007.

MARTINELLI, Alberto. From World System to World Society? Journal of World-Systems Research, [s.l.], vol. 11 n. 2, p. 241-260, 2005.

ORTIZ, Isabel; BURKE, Sara; MOHAMED, Berrada; CORTÉS, Hernán. World Protests 2006-2013. New York: Initiative for Dialogue Policy and Friedrich-Ebert-Stiftung, 2013.

PESTOFF, Victor A. Between Markets and Politics: Co-operatives in Sweden. Frankfurt/Main: Campus, and Boulder, Col.: Westview, 1991.

SCIPES, Kim. Building Global Labor Solidarity Today: Learning from the KMU of the Philippines. Class, Race and Corporate Power, vol. 3 n.1, 2014. Disponível em: http://digitalcommons.fiu.edu/classracecorporatepower/vol3/iss 1/4. Acesso em 29 jun. 2021. 
VAN DER LINDEN, Marcel. Workers of the World: Essays toward a Global Labor History. Chicago: Haymarket, 2010.

VAN DER LINDEN, Marcel. The Crisis of the World's Old Labour Movements. In: BIELER, Andreas; ERNE, Roland; GOLDEN, Darragh; HELLE, Idar; KJEDSTADLI, Knut; MATOS, Tiago; STAN, Sabina. Labour and Transnational Action in Times of Crisis. London: Rowman and Littlefield, 2015.

VISSER, Jelle. Union Membership Statistics in 24 Countries. Monthly Labour Review, [s.l.], p. 38-49, 2006.

Esse artigo foi originalmente publicado na Global Labour Journal. A reprodução do artigo neste dossiê foi autorizada tanto pelo autor, quanto pela revista. Referência completa: VAN DER LINDEN, Marcel. Global Labour: A Not-so-grand Finale and Perhaps a new Beginning. Global Labour Journal, [s.l.], vol. 7, n. 2, mai. 2016 (dossiê especial). Disponível em: https://mulpress.mcmaster.ca/globallabour/article/view/2941. Acesso em: 29 jun. 2021. Tradução de Ricardo Framil Filho e revisão de Katiuscia Moreno Galhera. 